\title{
SISTEM INFORMASI PENDAFTARAN MUSABAQAHTILAWATIL QURAN (MTQ) KABUPATEN SUMBAWA BERBASIS WEB
}

\author{
Yuniar Andriani ${ }^{1)}$, Eri Sasmita Susanto ${ }^{2)}$, M. Julkarnain ${ }^{3)}$ \\ ${ }^{1)}$ Mahasiswa Informatika,Universitas Teknologi Sumbawa \\ 2) Dosen Informatika, Universitas Teknologi Sumbawa \\ ${ }^{3}$ Dosen Informatika,Universitas Teknologi Sumbawa \\ Email: yuyunyulidiana@gmail.com ${ }^{1)}$, 92.eriss@ gmail.com ${ }^{2)}$, m.julkarnain@uts.ac.id ${ }^{3)}$
}

\begin{abstract}
Abstraksi
Musabaqah Tilawatil Qur'an (MTQ) merupakan kegiatan keagamaan yang cukup besar dilakukan secara rutin setiap tahunnya salah satunya di Kabupaten Sumbawa. Penelitian ini bertujuan membangun sebuah sistem informasi yang berbasis WEB, yaitu, Aplikasi Pendaftaran Musabaqah Tilawatil Qur'an (MTQ) pada Kabupaten Sumbawa. Aplikasi ini dibanggun mrnggunakan model bahasa pemrogramman PHP dengan menggunakan MySql sebagai databasenya.Metode pengembangan perangkat lunak menggunakan Extreme Programming (XP) Pengujian perangkat lunak dilakukan melalui pengujian black-box.Teknik pengumpulan data pada penelitian menggunakan observasi, wawancara, dokumentasi dan studi pustaka.Hasil akhir dari penelitian ini adalah aplikasi pendaftaran Musabaqah Tilawatil Qur'an (MTQ) Kabupaten Sumbawa Berbasis WEB yang berguna untuk membantu pengolahan data pendaftaran pesrtaMusabaqah Tilawatil Qur'an (MTQ) Kabupaten Sumbawa.

Kata Kunci: KEMENAG, Aplikasi PendaftaranExtreme Programming (XP)
\end{abstract}

\begin{abstract}
Musabaqah Tilawatil Qur'an (MTQ) is a large religious activity that is routinely carried out annually, one of which is in Sumbawa Regency. This study aims to build an information system based on WEB, namely, Application of Musabaqah Tilawatil Qur'an Registration (MTQ) in Sumbawa Regency. This application is built using the PHP programming language model using MySql as its database. Software development method uses Extreme Programming (XP) Software testing is done through black-box testing. Data collection techniques in research using observation, interviews, documentation and literature study. The end of this research is the application of registration of Musabaqah Tilawatil Qur'an (MTQ) of Sumbawa Regency based on WEB, which is useful to help the processing of registration data of the Muslim Brotherhood in Tilawatil Qur'an (MTQ) of Sumbawa Regency.

Keywords: Ministry of Religion, Application of Extreme Programming Registration (XP)
\end{abstract}

\section{PENDAHULUAN}

\section{A. Latar Belakang}

Pengetahuan teknologi saat ini khususnya teknologi informasi telah berkembang sangat pesat, dengan perkembangan teknologi setiap tahun dalam pekerjaan akan dapat direalisasikan lebih efektif dan efesien. Perkembangan teknologi dalam menjalankan aktifitas manusia merasa lamban dan dapat membutuhkan banyak waktu.Namun munculnya teknologi segala aktifitas dapat dilakukan dengan cepat dengan waktu yang lebih singkat seperti dalam dunia pendidikan, kesehatan, keuangan, dan keagamaan yang saat ini berpijak pada kemampuan untuk mengikuti perkembangan teknologi dengan kemampuan mengakses serta menyajikan informasi. Dalam hal ini dapat meningkatkan kualitas pendidikan keagaman sudah saatnya memiliki informasi yang dapat membantu dalam mengelola data-data. Dengan menggunakan sistem yang terkomputerisasi maka semua data yang dikelolah dapat tersimpan dengan rapi dan akurat.

Musabaqah Tilawatil Qur'an (MTQ) adalah warisan budaya yang telah menjadi sebagai kegiatan keagamaan yang cukup besar dilakukan secara rutin setiap tahunnya salah satunya di Kabupaten Sumbawa.Dengan adanya kegiantan ini sangat berperan penting sebagai wadah untuk meningkatkan minat dan keahlian dalam membaca Al-Qur'an bagi masyarakat, sehingga masyarakat dapat mencapai visi misi yang diinginkan.Biasanya event Musabaqah Tilawatil Qur'an (MTQ) ini diadakan dari tingkat Desa, 
Kecamatan, Kabupaten, Propensi, bahkan Nasional.

Pemerintah Kabupaten Sumbawa menyelenggarakan event Musabaqah Tilawatil Qur'an (MTQ) yang di ikuti oleh 24 Kecamatan di Kabupaten Sumbawa. Adapun jenis kegiata yang akan di perlombaan seperti, Tilawah Alquran, Tahfizh Alquran, Tafsir Qur'an, Fahmil Qur'an, Syarhil Qur'an, Khattil Qur'an. Musabaqah Makalah Ilmiah Qur'an (M2IQ) dan lain-lain.Pada masing-masing cabang itu terdapat golongan dan tingkatan-tingkatannya pula. Melalui kegiatan ini, citra bahwa islam memiliki suatu keistimewaan yang harus dibanggakan dan dapat menjadi nilai tambah penguatan dalam kehidupan beragama. diharapkan agar masingmasing pemegang kebijakan di semua wilayah mendorong dan mendukung aktivitas-aktivitas pembelajaran Al-Qur'an.

Kabupaten sumbawa belum memanfaatan teknologi informasi salah satunya pada sistem pendaftaran Musabaqah Tilawatil Qur'an (MTQ) belum dimanfaatkan secara maksimal. dimana pada kegiatan tersebut saat ini belum memiliki sistem informasi dan sistem pendaftaran secara terkomteresasi. Sedangkan Sistem pendaftaran adalah suatu sistem yang digunakan untuk mengelola informasi dan data-data peserta sehingga dapat memberikan kemudahan kepada pesrta maupun panitia. Namun dalam proses sistem pendaftarannya masih dilakuukan secara manual.

Oleh karena itu dibutuhkan media yang bisa digunakan sebaga media yang terkomputerisasi. Dari permasalahan tersebut penulis bermaksud mencoba membangun Aplikasi Pendaftaran Musabaqah Tilawatil Qur'an (MTQ) agar proses pendaftaran dapat berjalan dengan cepat.

Dengan adanya Aplikasi Pendataran Musabaqah Tilawatil Qur'an (MTQ) ini diharapkan dapat memberikan dan mempermudah perkejaan bagian panitia dalam mengelolah data pendaftaran peserta (MTQ) Serta mempermudahkan dalam pelaporan jumlah peserta dan menjadi salah satu cara untuk meningkatkan kualitas peserta.

\section{B. Tujuan Penelitian}

Tujuan penelitian dari pembuatan tugas akhir ini adalah menghasilkan Aplikasi Pendaftaran Musabaqah Tilawatil Qur'an (MTQ) Di Kabupaten Sumbawa Berbasis Web yang dapat mempermudah peserta dalam proses pendaftaran yang disajikan dalam bentuk Web.

\section{Batasan Masalah}

Berdasarkan perumusan masalah yang telah di bahas, maka dilakukan pembatasan masalah yaitu:

a. Sistem Pendaftaran Musabaqah Tilawatil Qur'an (MTQ) hanya tingkat Kabupaten di kabupaten Sumbawa.

b. Data peserta Musabaqah Tilawatil Qur'an (MTQ) tingkat Kabupaten di Kabupaten Sumbawa.

c. Sistem dibangun dengan bahasa pemrograman $P H P$ dan database $M Y S Q L$.

d. Metode pengumpulan data menggunakan Observasi, Wawancara, dan Studi Pustaka.

e. Metode pengembangan perangkat lunak menggunakan metode Extreme Programming ( $x p)$

f. Sistem ini menggunakan pengujian Black Box Testing.

\section{TINJAUAN PUSTAKA}

Perancangan Aplikasi Pembelajaran Membaca Alqur'an Dengan Metode Qiro'ah Berbasis Android, oleh Tri Tiastari Nur, (2013). Dalam penleitian yang dilakukan oleh Tri Tiastari Nurmerancang Aplikasi Pembelajaran membaca Al-Qur'an melalui suatu alat komunikasi yang disebut smartphone. Alat komunikasi ini dapat sangat membantu orang yang ingin belajar membaca AlQur'an karena dapat dibawah kemana saja. Dalam melakukan penelitian ini, jenis penelitian yang digunakan adalah penelitian eksperimental yaitu melakukan eksperimen terhadap variabel-variabel kontrol (input) untuk menganalisis output yang dihasilkan.

Abd Hamid Abdulloh "Pemanfaatan Data EKtp Dalam Proses Validasi Peserta Musabaqoh Tilawatil Qur'an (MTQ)" (2014) melakukan penelitian

Rancang bangun aplikasi yang terkait dalam pelaksana pembelajaranataupun kegiatan yang di selenggarakan seperti event-event Musabaqah Tilawatil Qur'an (MTQ). Yakni penelitian yang berjudul

Dari perbandingan beberapa penelitian yang telah dipaparkan diatas, maka penulis juga akan melakukan perancangan dan pembangunanAplikasi Pendaftaran Musabaqah Tilawatil Qur'an (MTQ) Kabupaten Sumbawa Berbasis Web yang bertujuan:
a. Dapat membantu pekerjaan panitia mengelolah data pesertaMTQ yang 
sebelumnya masih manual dengan pesrta megisi formulir dari panitia pengumuman, sehingga dengan dibangunnya Aplikasi pendaftaran MTQ ini mampu membuat pekerjaan bagian admin lebih efektif dan efesien.

b. Mempermudah peserta maupun panitiapenyelenggara dalam memperoleh informasi terkait pendaftaran pengumuman jumlah peserta, dan laporan.

\section{A. Definisi Rancang Bangun}

Rancang merupakan serangkaian prosedur untuk menerjemahkan hasil analisis dari sebuah sistem kedalam bahasa pemrograman untuk mendeskripsikan dengan detail bagaimana komponen-komponen sistem diimplementasikan. Sedangkan pengertian bangun atau pembangunan sistem adalah kegiatan mencipatakan baru maupun mengganti atau memperbaiki sistem yang telah ada baik secara keseluruhan maupun sebagian (Pressman, 2002).

Rancang bangun sangat berkaitan dengan perancangan sistem yang merupakan satu kesatuan untuk merancang dan membangun sebuah aplikasi.Perancangan sistem adalah penentuan proses dan data yang diperlukan oleh sistem baru. Jika sistem itu berbasis komputer, rancangan dapat menyertakan spesifikasi jenis peralatan yang akan digunakan (Tata Sutabri, 2005).

Perancangan sistem dapat didefinisikan sebagai gambaran, perencanaan, dan pembuatan sketsa atau pengaturan dari beberapa elemen yang terpisahkan kedalam satu kesatuan yang utuh dan berfungsi.Tujuan dari perancangan sistem yaitu untuk memenuhi kebutuhan para pemakai sistem dan memberikan gambaran yang jelas dan rancang bangun yang lengkap kepada programmer.Kedua tujuan ini lebih berfokus pada perancangan atau desain sistemyang terinci yaitu pembuatan rancang bangun yang jelas dan lengkap yang nantinya digunakan untuk pembuatan program komputernya (Jogiyanto, 2001).

Dari penjelasan diatas dapat disimpulkan rancang bangun sistem merupakan kegiatan menterjemahkan hasil analisa kedalam bentuk paket perangkat lunak kemudian menciptakan sistem tersebut atau memperbaiki sistem yang ada.

\section{B. Aplikasi}

Aplikasi adalah program yang berisikan perintah-perintah untuk melakukan pengolahan data (Jogiyanto, 2004).
Aplikasi adalah sebuah perangkat lunak yang berkedudukan sebagai front end dalam suatu sistem yang digunakan untuk mengolah data menjadi suatu informasi yang berguna bagi orang-orang dan sistem yang bersangkutan (Sry Widianti, 2000).

Menurut Dhanta (2009:32), aplikasi (application) adalah software yang dibuat oleh suatu perusahaan komputer untuk mengerjakan tugas-tugas tertentu, misalnya Microsoft Word, Microsoft Excel.

Berdasarkan ketiga definisi diatas, penulis menyimpulkan bahwa aplikasi adalah pemanfaatan teknologi komputer dengan membuat system / program agar data dapat diolah serta lebih berdaya guna secara optimal.

\section{Definisi Web}

Pada bagian ini, penulis menjelaskan tentang definisi web menurut Sidik (2017) dan Solusindo (2008).Secara umum keduanya mengemukakan bahwa definisi dari web hampir serupa.

Sidik (2017) mendefinisikan bahwa web adalah server web yang digunakan untuk keperluan publikasi dokumen HTML tetapi juga bisa platform untuk aplikasi internet yang interaktif dengan menggunakan browser web sebagai klien dari aplikasinya. Sedangkan Solusindo (2008) mendefinisikan bahwa web merupakan sebuah situs web yang di hosting di serverweb dan dapat diakses dari browser menggunakan domain tertentu.

Berdasarkan pendapat yang telah dikemukakan diatas dapat disimpulakan bahwa web merupakan layanan yang didapat oleh pemakai komputer yang terhubung ke internet, baik berupa teks, gambar, suara, video, yang interaktif dan mempunya kelebihan untuk menghubungkan (link) satu dokumen dengan dokumen lainnya (hypertext) yang dapat diakses melalui sebuah browser.

\section{METODE PENELITIAN}

Metode yang digunakan dalam penelitian ini adalah penelitian deskriptif kualitatif yang dimana menurut Moleong (2016: 11) deskriptif kualitatif artinya mencatat dengan teliti berbagai fenomena yang dilihat dan didengar serta dibaca via wawancara atau catatan lapangan, foto, video tape, dokumentasi pribadi, catatan serta memo dan lain-lain. Peneliti harus membandingbandingkan, mengabstraksikan dan menarik kesimpulan.Dalam penelitian deskriptif kualitatif 
jenis data yang dikumpulkan berupa kata-kata, gambar dan bukan angka-angka. Hal ini dikarenakan berbagai data yang terkumpul kemungkinan menjadi kunci terhadap apa yang akan atau sudah diteliti.

Penelitian ini termasuk ke dalam jenis penelitian kualitatif yang bersifat deskriptif.Penggunaan tipe deskriptif dimaksudkan sebagai prosedur pemecahan masalah yang diselidiki dengan menggambarkan keadaan subjek atau objek yang diteliti pada saat sekarang berdasarkan fakta-fakta yang tampak atau sebagaimana adanya. Adapun alur dalam penelitian ini dilakukan agar dalam penelitian tersebut mempunyai arahan kegitan penelitian, sehingga tujuan yang diharapkan dapat tercapai dengan baik.

Adapun alur proses penelitian adalah seperti berikut ini :



Gambar 1. Alur Penelitian

\section{A. Identifikasi Masalah}

Dalam tahap ini, dilakukan pengidentifikasian masalah yang didahului dengan mempelajari masalah tersebut sehingga ditemukan permasalah pokok yang dijadikan sebagai dasar penelitian tugas akhir.

\section{B. Metode Pengumpulan Data}

Pengumpulan data adalah teknik atau cara yangdilakukan untuk memperoleh informasi yang dibutuhkan dalam rangka mencapai tujuan penelitian. Metode Penelitian ini menjelaskan bahwa sumber data adalah subjek dari mana data diperoleh. Adapun metode yang digunakan dalam proses pengumpulan data, antara lain :

a. Wawancara

Pada tahap ini penulis melakukan pengumpulan data melalui tanya jawab dan diskusi secara langsung mengenai sistem pendaftaran Musabaqah Tilawatil Qur'an (MTQ). Dengan hal ini untuk mendapatkan informasi terkait dengan penelitian maka dari itu penulis melakukan wawancara langsung denganIbu Anggi selaku kariawan di Bagian Pemeritahan pada Pemerintahan Daerah (PEMDA) Kabupaten Sumbawa.

b. Observasi

Tahap ini merupakan metode pengumpulan data dengan cara observasi tinjauan secara langsung ke Pemerintahan Daerah (PEMDA) Kabupaten Sumbawa agar mendapatkan data yang bersifat nyata dan meyakinkan. Maka penulis melakukan pengamatan secara langsung mengenai sistem yang berjalan tentang pendaftaran Musabaqah Tilawatil Qur'an (MTQ).

c. Studi Pustaka

Studi pustaka merupakan salah satu tahapan selanjutnya yaitu untuk mendapatkan datadata yang bersifat teoritis. Maka penulis memperoleh data dengan meampelajari konsep, teknik, dan informasi yang bersumber dari buku-buku, jurnal, internet, dan referensi lainya yang berkaitan dengan sistem informasi yang akan di bangun.

\section{Metode Pengembangan Perangkat Lunak}

Metode pengembangan perangkat lunak merupakan moedel metode yang di gunakan dalam membagun AplikasiPendaftran Musabaqah Tilawatil Qur'an (MTQ) Kabupaten Sumbawa Berbasi Web. Model metode yang digunakan adalah Extreme Programming $(X P)$ model inidipilih agar penulis dapat menyelesaikan penelitiannya dengan baik dan tepat waktu, penelitian ini harus dilakukan sesuai dengan prosedur yang telah ditetapkansebagai berikut :

a. Planning (Perencanaan)

Pada tahap perencanaan ini dimulai dari pengumpulan kebutuhan yang membantu tim tehnikal untuk memahami konteks target atau sasaranyang ingin dicapai dalam peningkatan proses ataupun permasalahan yang ingin dipecahkan.Selanjtunyamenentukan langkahlangkah yang akan dilakukan untuk mencapai 
target atau sasaran yang telah ditetapkan tersebut dengan anlisa kebutuhan data guna memperoleh data terkait sistem informasi yang akan dibangun dengan melakukan metode observasi, wawancara dan studi pustaka.

b. Design(Perancangan)

Tahapan selanjutnya penulis mulai mendesign AplikasiPendaftran Musabaqah Tilawatil Qur'an (MTQ) Kabupaten Sumbawa Berbasi Webmenggunakan permodelan sistem DFD (Data Flow Diagram) dan ERD (Entity Relationship Diagram) untuk memberi gambaran alur sistem infromasi yang akan dibangun.

c. Coding (Pengkodean)

Pada tahap ini penulis melakukan Konsep utama dari tahapan pengkodean merupakan proses membuat aplikasi yang sesuai dengan penyusun pada tahap perencanaan dan perancangan.Dalam hal ini penulis melakukan penulisan kode program pada pembuatan Aplikasi Pendaftran Musabaqah Tilawatil Qur'an (MTQ) Kabupaten Sumbawa Berbasi Webdengan menggunakan bahasa pemrogramman PHP

d. Testing(Pengujian)

Pada tahap ini Setelah dilakukan penulisan kode program kemudian tahap selanjutnya melakukan pengujian, yaitu untuk menguji fungsinonalitasAplikasiPendaftran

Musabaqah Tilawatil Qur'an (MTQ) sistemdan untuk mengetahui kesalahan interface yang terjadi pada saat sistem dijalankan.Dalam pengujiannya menggunakan pengujian black box testing.

Kelebihan yang dimiliki metode pengembangan Extreme Programming (XP) adalah pembangunan sistem yang dibuat lebih cepat, dapat menjalin komunikasi dan meningkatkan kepuasan klien serta meningkatkan komunikasi dan sifat saling menghargai antar developer.

\section{HASIL DAN PEMBAHASAN}

Dalam penelitian ini adapun tahapan yang dilakukan berdasarkan dengan metode pengembangan perangkat lunak yang digunakan yaitu metode Extreme Programming (XP) dalam membangun Aplikasi Pendaftaran Musabaqah Tilawatil Qur'an (MTQ) Kabupaten Sumbawa Berbasis Web.Dalam bab ini penulis akan membahas tentang tahapa-tahapan dalam membangun aplikasi seperti tahapan
Perencanaan, Perancangan, Pengkodean, sampai ke tahapan Pengujian seperti Berikut ini :

\section{A. Planning (Perencanaan)}

Berikut ini merupakan perencanaa dalam pembuatan Aplikasi Pendaftaran Musabaqah Tilawatil Qur'an (MTQ) Kabupaten Sumbawa Berbasis Web sebagai berikut :

\section{a.Pengumpulan Data}

Pada tahap ini, adapun yang dilakukan oleh penulis pada tahapan ini yaitu adanya analisis terhadap kebutuhan pengguna dan menganalisis kebutuhan perangkat lunak dalam pembuatan Aplikasi. Perangkat lunak yang digunakan dalam pembuatan Aplikasi ini adalah perangkat lunak sistem Windows 10, Xampp, PHP dengan database MySQL, Sublimetext, Black Box, danVisio 2013. Dalam pengumpulan data yang dilakukan pada tahap ini yaitu dengan cara observasi, wawancara dan studi pustaka seperti berikut ini:

Observasi

Pada tahap observasi dilakukan tinjauan atau pengamatan secara langsung pada Kantor Kementerian Agama (KEMENAG) penulis memperoleh data yang berkaitan dengan Pendaftaran Musabaqah Tilawatil Qur'an (MTQ) yang penulis lampirkan pada bagian lampiran penelitian ini.

Wawancara

Adapun wawancara yang dilakukan penulis dengan salah satu kariawan (KEMENAG) sehingga penulis mengetahui permasalahan yang terkait dengan Pendaftaran Musabaqah Tilawatil Qur'an (MTQ) serta alur sistem yang berjalan saat ini.

Studi pustaka

Studi pustaka yang digunakan untuk memperoleh data maupun informasi dalam penelitian ini meliputi buku referensi yang berkaitan dengan aplikasi, pemrograman web, rekayasa perangkat lunak, dan PHP.Kemudian jurnal dan tugas akhir yang berkaitan dengan penelitian atau aplikasi yang dibangun.

\section{b. Flowmap Berjalan}

Adapun flowmap yang sedang berjalan pada proses sistem pendaftaran (MTQ) sebagai berikut: 


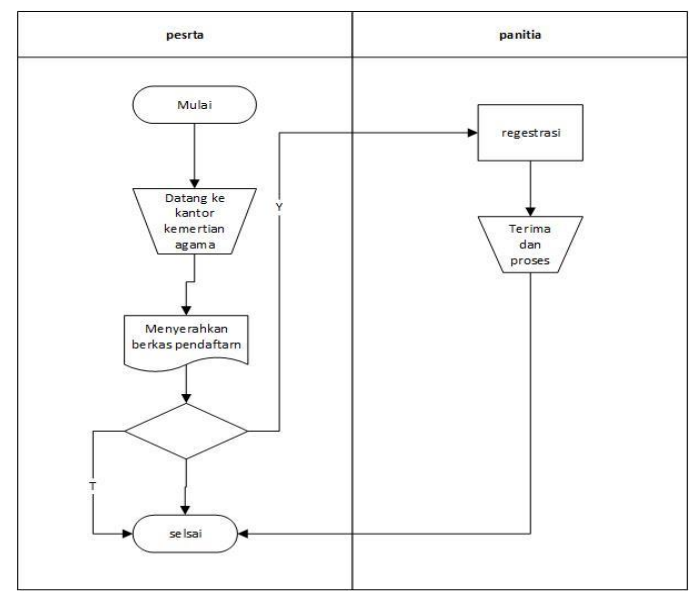

Gambar 2. Flowmap Berjalan

\section{c. Flowmap Usulan}

Berdasarkan masala-masalah yang telah di sajikan sebelumnya penulis mengusulkan membuat sebuah aplikasi yang dapat membantu perkerjaan dari proses pendaftran (MTQ). Adapun flowmap yang di usulkan yaitu Aplikasi Pendaftaran Musabaqah Tilawatil Qur'an (MTQ) Kabupaten Sumbawa Berbasis Web seperti berikut ini :



Gambar 3. Flowmap Alur Usulan

\section{B. Design (Perancangan)}

Adapun tahapan dalam pembuatan Aplikasi Pendataran Musabaqah Tilawatil Qur'an (MTQ) Kabupaten Sumbawa Berbasis Web meliputi tahapan perancangan menggunakan Unified Modelling Language (UML). (UML) merupakan rancangan dari struktur aplikasi yang akan dibangun yang terdiri dari Usecase Diagram, Class Diagram, Activity Diagram dan Sequence Diagram. Selanjutnya perancangan interface.

\section{a. Use Case Diagramuser}

Dalam use case diagram dijelaskan actor yang terlibat dalam aplikasi yang dibangun dan proses-proses yang terjadi di dalamnya Adapun perancangan Aplikasi Pendaftaran Musabaqah Tilawatil Qur'an (MTQ) Kabupaten Sumbawa Berbasis Web yang menggambarkan semua alur kerja aplikasi yang akan dibangun sebagai berikut, Adapun perancangan Usecase Diagram dari Aplikasi Pendaftaran Musabaqah Tilawatil Qur'an (MTQ) Kabupaten Sumbawa Berbasis Web sebagai berikut ini :



Gambar 4. Usecase Diagram User

b. Use Case Diagram Admin

Adapun perancangan Usecase Diagram dari Aplikasi Pendaftaran Musabaqah Tilawatil Qur'an (MTQ) Kabupaten Sumbawa Berbasis Web sebagai berikut ini :

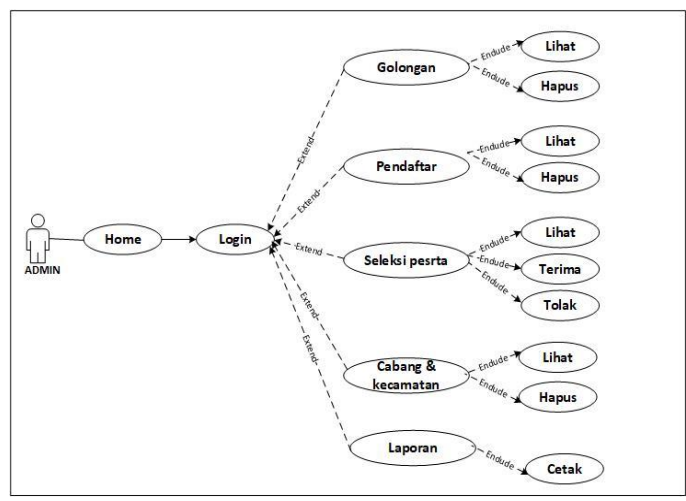

Gambar 5. Usecase Diagram Admin 
c. Activitiy DiagramUser

Adapun perancangan Activity diagram user dari Aplikasi Pendaftaran Musabaqah Tilawatil Qur'an (MTQ) Kabupaten Sumbawa Berbasis Web sebagai berikut ini :

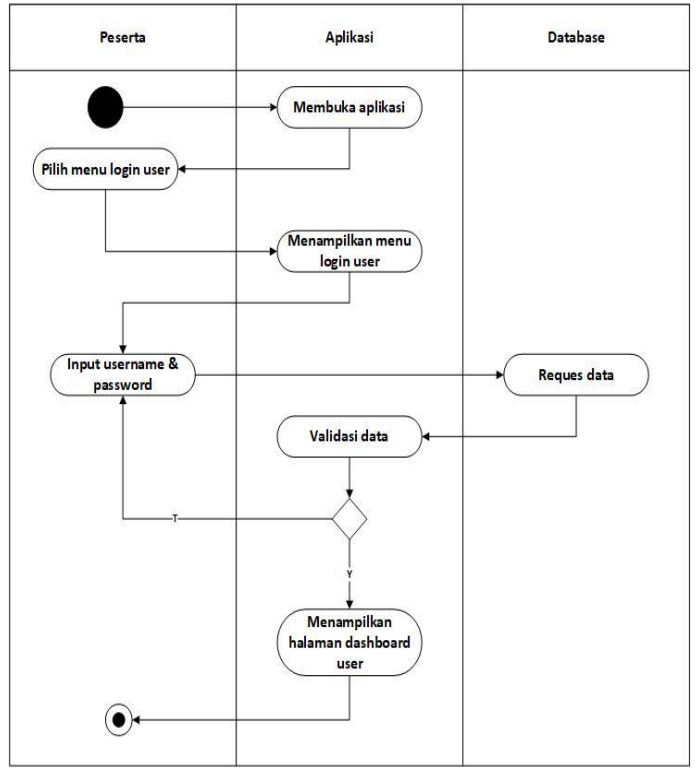

Gambar 6.Activity Diagram User

d. Activitiy DiagramAdmin

Adapun perancangan Activity diagram pendaftaran user dari Aplikasi Pendaftaran Musabaqah Tilawatil Qur'an (MTQ) Kabupaten Sumbawa Berbasis Web sebagai berikut ini :

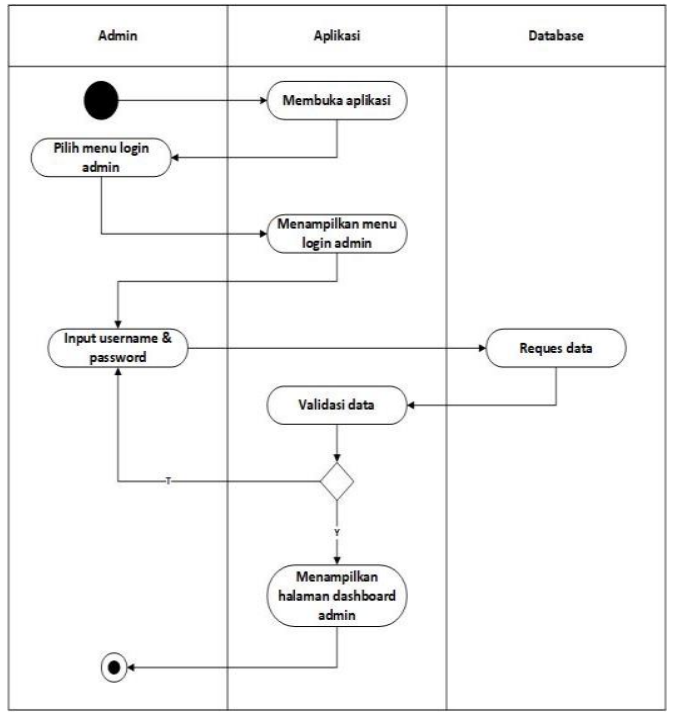

Gambar 7. Activity Diagram Admin e. Sequencial Diagram User

Adapun perancangan

sequencial diagram dari Aplikasi Pendaftaran Musabaqah Tilawatil Qur'an (MTQ) Kabupaten Sumbawa Berbasis Web sebagai berikut ini :



Gambar 8.Sequencial Diagram User

f. Sequencial Diagram Admin dapun perancangan sequencial diagram dari Aplikasi Pendaftaran Musabaqah Tilawatil Qur'an (MTQ) Kabupaten Sumbawa Berbasis Web sebagai berikut ini :

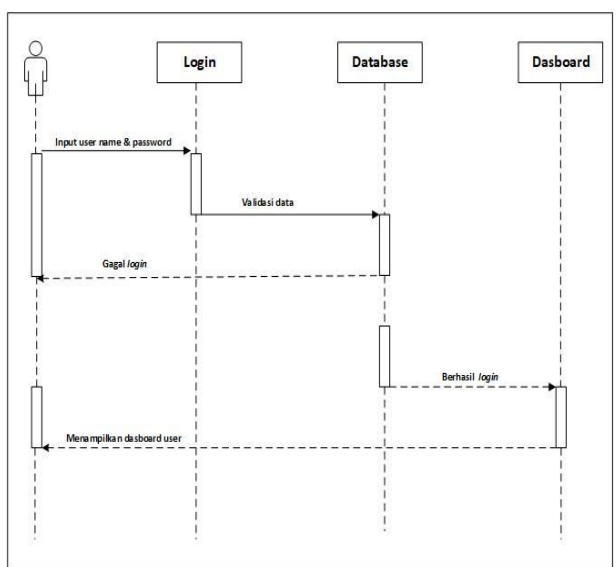

Gambar 9. Sequencial Diagram Admin 


\section{g. Class Diagram}

Class diagram adalah diagram yang digunakan untuk menampilkan beberapa kelas yang ada dalam sistem perangkat lunak.Class diagram menunjukkan hubungan antar class dalam sistem yang sedang dibangun dan bagaimana mereka saling berkolaborasi untuk mencapai suatu tujuan.Adapun rancangan struktur class diagram dari Aplikasi Pendaftaran Musabaqah Tilawatil Qur'an (MTQ) Kabupaten Sumbawa Berbasis Web sebagai

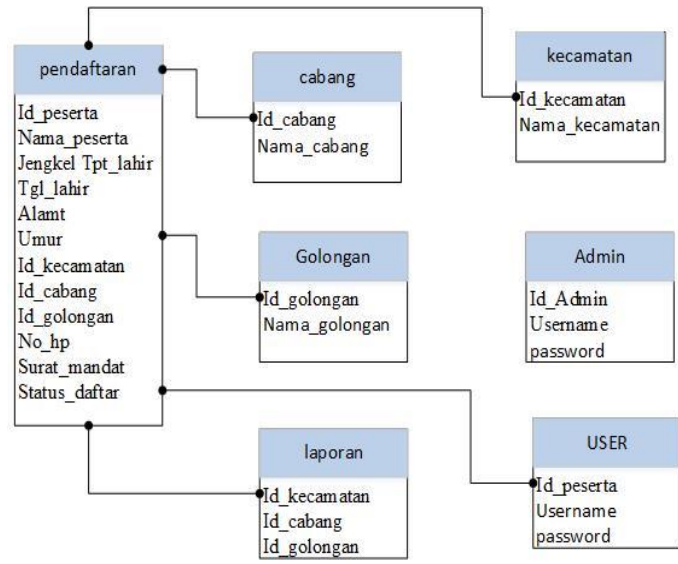

Gambar 10. Class Diagram Aplikasi Pendaftaran Musabaqah Tilawatil Qur'an (MTQ)

h. Racangbangun user

Berikutini adalah rancangan tampilan halaman utamadari pembuatanAplikasi Pendaftaran Musabaqah Tilawatil Qur'an (MTQ) Kabupaten Sumbawa Berbasis Webseperti gambaryang di bawah ini :



Gambar 11. Rancangan user i. Halaman dashboard admin

Berikut ini adalah rancangan menu halaman dashboardadmin dari pembuatanAplikasi Pendaftaran Musabaqah Tilawatil Qur'an (MTQ) Kabupaten Sumbawa Berbasis Webseperti gambaryang di bawah ini :



Gambar 12. Dashboard Admin

C. Coding (Pengkodean)

Berikut ini adalah hasil dari perancangan yang telah disusun sebelumnya Sesuai dengan pembuatan Aplikasi Pendaftaran Musabaqah Tilawatil Qur'an (MTQ) Kabupaten Sumbawa Berbasis Web. Pada pembuatan Aplikasi ini menggunakan bahasa pemrograman PHP dengan editor Sublime Text dan menggunakan Database MySQL, Adapun kode programdari Aplikasi Pendaftaran yang telah dibangun ini tercantum pada lampiran.

Berikut ini merupakan implementasi dari kode program pembuatanAplikasi Pendaftaran Musabaqah Tilawatil Qur'an (MTQ) Kabupaten Sumbawa Berbasis Webseperti gambaryang di bawah ini:

a. Implementasi Hasil Kode Program

Berikut merupakan Implementasi hasil kode program tampilan halaman utama dari pembuatanAplikasi Pendaftaran Musabaqah Tilawatil Qur'an (MTQ) Kabupaten Sumbawa Berbasis Webseperti gambaryang di bawah ini: 




Gambar 13. Halaman Utama

\section{Testing (Pengujian)}

Adapun hasil dari pengujian perangkat lunak yang dilakukan menggunakan pengujian black boxyaitu pengecekan pada fungsionalitas Aplikasi Pendaftaran (MTQ), dalam pegujian ini dibagi menjadi 2 yaitu pegujian untuk peserta dan pegujian untuk Admin. Fungsionalitas input dan output untuk menentukan apakah keluaran sudah sesuai dengan yang diharapkan. Metode black box merupakan metode pengujian yang menggunakan dari rancangan untuk melakukan proses uji coba antara lain:

a. Pegujian LoginPeserta

Adapun pegujian peserta hasil dari pembuatan Aplikasi Pendaftaran Musabaqah Tilawatil Qur'an (MTQ) Kabupaten Sumbawa Berbasis Webseperti berikut ini :

\begin{tabular}{|l|l|l|}
\hline \multicolumn{2}{|c|}{ Tabel 1 pengujian user } \\
\hline Kasus dan Hasil Uji (Data Normal) \\
\hline Aksi Aktor & $\begin{array}{l}\text { Hasil Yang } \\
\text { Diharapkan }\end{array}$ & $\begin{array}{c}\text { Hasil } \\
\text { Pengujian }\end{array}$ \\
\hline $\begin{array}{l}\text { Memasukk } \\
\text { an } \\
\text { username } \\
\text { dan } \\
\text { password } \\
\text { sesuai } \\
\text { dengan } \\
\text { data Lalu } \\
\text { menekan } \\
\text { button } \\
\text { login }\end{array}$ & $\begin{array}{l}\text { Malaman } \\
\text { dasboard } \\
\text { login peserta } \\
\text { sesuai hak } \\
\text { akses untuk } \\
\text { peserta }\end{array}$ & Berhasil \\
\hline
\end{tabular}

\begin{tabular}{|c|c|c|}
\hline $\begin{array}{l}\text { Username } \\
\text { dan } \\
\text { password } \\
\text { kosong } \\
\text { atau } \\
\text { username } \\
\text { dan } \\
\text { paswword } \\
\text { salah Lalu } \\
\text { menekan } \\
\text { button } \\
\text { login }\end{array}$ & $\begin{array}{l}\text { Tampil } \\
\text { kembali } \\
\text { halaman } \\
\text { Login yang } \\
\text { berisi } \\
\text { peringatan } \\
\text { bahwa } \\
\text { username } \\
\text { atau } \\
\text { password } \\
\text { salah silakan } \\
\text { memasukkan } \\
\text { username } \\
\text { dan } \\
\text { passwordke } \\
\text { mbali }\end{array}$ & 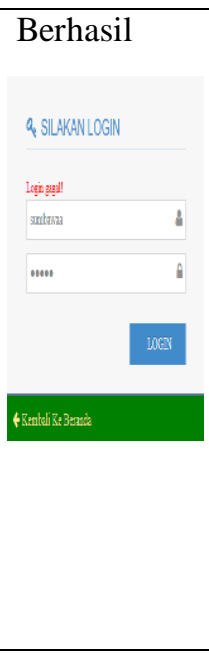 \\
\hline \multicolumn{3}{|c|}{ Kasus dan Hasil Uji (Data Normal) } \\
\hline $\begin{array}{l}\text { Memasukk } \\
\text { an data } \\
\text { pesertasesu } \\
\text { ai dengan } \\
\text { data sesuai } \\
\text { dengan } \\
\text { persyarata } \\
\text { n yang } \\
\text { telah di } \\
\text { tentukan } \\
\text { Lalu } \\
\text { menekan } \\
\text { button } \\
\text { login } \\
\end{array}$ & $\begin{array}{l}\text { Muncul } \\
\text { halaman } \\
\text { pendaftarpes } \\
\text { ertamegisi } \\
\text { sesuai } \\
\text { dengan data } \\
\text { peserta dan } \\
\text { data } \\
\text { tersimpan }\end{array}$ & 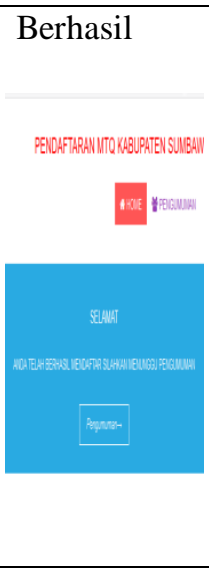 \\
\hline \multicolumn{3}{|c|}{ Kasus dan Hasil Uji (Data Tidak Normal) } \\
\hline $\begin{array}{l}\text { Mengisi } \\
\text { Data } \\
\text { kosong }\end{array}$ & $\begin{array}{l}\text { Tampil } \\
\text { kembali } \\
\text { halaman } \\
\text { pendaftar } \\
\text { yang berisi } \\
\text { peringatan } \\
\text { bahwa harus } \\
\text { mengisi } \\
\text { kembali } \\
\text { semua data- } \\
\text { data peserta }\end{array}$ & $\frac{5}{5=}$ \\
\hline
\end{tabular}

\section{KESIMPULAN DAN SARAN}

\subsection{Kesimpulan}

Berdasarkan hasil penelitian pada KEMENAG kabupaten sumbawa tentang Pendaftaran Musabaqah Tilawatil Qur'an (MTQ) tingkat kabupaten yang telah selesai penulis rancang dan membangun yaitu Aplikasi 
Pendaftaran Musabaqah Tilawatil Qur'an (MTQ) Kabupaten Sumbawa Berbasis Web.Dalam membangun aplikasi ini mengunakan metode Extreme Programming(XP) dengan perancangan struktur Data Flow Diagram (DFD) dan bahasa pemrograman PHP dengandatabase MySQL, dimana telah menghasilkan aplikasi yang telah di uji dengan menggunakan metode Black Box Testing dan berhasil. adapun hasil dari penelitian ini diharapkan nantinya menjadi masukkan kepada pimpinan panitia Musabaqah Tilawatil Qur'an (MTQ) untuk menerapkan aplikasi pendaftaran yang berbasis digital ini untuk meningkatkan kualitaspeserta.

\subsection{Saran}

Adapun saran yang dapat penulis berikan untuk pengembangan atau perbaikan kedepannya sebagai berikut :

1. Menambahkan fitur-fitur lain seperti fitur penilaian dari juri, fitur pengumuman pemenang dari peserta, informasi jumlah nilai, dan fitur melakukan permohonaan izin sehingga peserta lebih mengetahui informasi lainnya yang berhubungan dengan informasi jadwal pelaksana kegiatan.

2. Diharapkan aplikasi yang telah dibagun ini dapat untuk segera di hosting oleh pihak KEMENAG agar dapat digunakan.Tampilan website antar muka dapat dibuat menjadi lebih menarik.

b. Pengujian Logi Admin

Adapun pegujian Admin hasil dari pembuatan Aplikasi Pendaftaran Musabaqah Tilawatil Qur'an (MTQ) Kabupaten Sumbawa Berbasis Web seperti berikut ini :

Kasus dan Hasil Uji (Data Normal)

\begin{tabular}{|l|l|c|}
\hline Aksi Aktor & $\begin{array}{l}\text { Hasil Yang } \\
\text { Diharapkan }\end{array}$ & $\begin{array}{c}\text { Hasil } \\
\text { Pengujian }\end{array}$ \\
\hline $\begin{array}{l}\text { Memasukk } \\
\text { an }\end{array}$ & $\begin{array}{l}\text { Muncul } \\
\text { halaman } \\
\text { username } \\
\text { dasboard } \\
\text { password } \\
\text { adminsesuai } \\
\text { hangsesuai }\end{array}$ & Berhasil \\
$\begin{array}{l}\text { Lalu } \\
\text { akses untuk } \\
\text { button } \\
\text { login }\end{array}$ & admin & \\
\hline
\end{tabular}

\begin{tabular}{|l|l|l|}
\hline \multicolumn{3}{|c|}{ Kasus dan Hasil Uji (Data Tidak Normal) } \\
\hline Username & Tampil & Berhasil \\
dan & kembali & \\
password & halaman & asukwoow \\
kosong & Login yang & \\
atau & berisi & $\ldots$ \\
username & peringatan & \\
dan & bahwa & \\
paswword & username & \\
salah Lalu & atau \\
menekan & password & \\
button & salah silakan & \\
login & memasukkan & \\
& username & \\
& dan & \\
& passwordke & \\
& mbali & \\
\hline
\end{tabular}

\section{Daftar Pustaka}

[1] Pressman, Roger S. 2002. Rekayasa PerangkatLunak, Buku Satu, diterjemahkan oleh: Harnaningrum L.N., Andi, Yogyakarta.

[2] Tata Sutabri. 2005. Analisis Sistem Informasi. Yogyakarta. Andi.

[3] Rizky Dhanta. 2009. Pengantar Ilmu Komputer. Surabaya: Indah.

[4]Mustaqball, Sidik M. 2015. "Pengujian Aplikasi Menggunakan Black Box Testing Boundary Value Analysis" Vol 1. No 3. Diakses tanggal Akses 09 Maret 2019.

[5]Solusindo, E-Media. 2008. MembangunKomunitas Online Secara Praktis dan Gratis. Jakarta: Elex Media Komputindo.

[6]Jogiyanto. 2001. Analisis \& Desain Sistem Informasi : pendekatan terstruktur teori dan praktek aplikasi bisnis. Yogyakarta : Andi.

[7] Widianti, Sri., 2000. Pegantar Aplikasi Basis Data. Jakarta: Penerbit: Fajar

[8] Rizky Dhanta. 2009. Pengantar Ilmu Komputer. Surabaya: Indah.

[9]Solusindo, E-Media. 2008. Membangun Komunitas Online Secara Praktis dan Gratis. Jakarta: Elex Media Komputindo.

[10]Pressman, Roger, S. (2012). Rekayasa Perangkat Lunak Pendekatan Praktisi Edisi 7. Yogyaka 